\title{
Correction to: Tendinopathy VISAs have expired-is it time for outcome renewals?
}

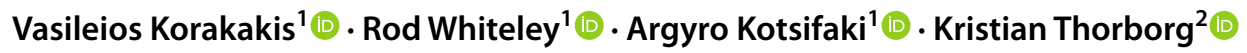

Published online: 24 September 2021

(c) European Society of Sports Traumatology, Knee Surgery, Arthroscopy (ESSKA) 2021

\section{Correction to: Knee Surgery, Sports Traumatology, Arthroscopy (2021) 29:2745-2748 https://doi.org/10.1007/s00167-021-06596-7}

The article "Tendinopathy VISAs have expired—is it time for outcome renewals?", written by Vasileios Korakakis, Rod Whiteley, Argyro Kotsifaki and Kristian Thorborg, was originally published online on 10 May 2021 with Open Access under a Creative Commons Attribution 4.0 International License. After publication in volume 29, issue 9, page 2745-2748 the author(s) decided to cancel the Open Access. Therefore, the copyright of the article has been changed on 26 August 2021 to (C) European Society of Sports Traumatology, Knee Surgery, Arthroscopy (ESSKA) 2021 with all rights reserved.
The original article has been corrected.

Publisher's Note Springer Nature remains neutral with regard to jurisdictional claims in published maps and institutional affiliations.

The original article can be found online at https://doi.org/10.1007/ s00167-021-06596-7.

Vasileios Korakakis

Vasileios.Korakakis@aspetar.com

1 Aspetar Orthopaedic and Sports Medicine Hospital, PO 29222, Doha, Qatar

2 Department of Orthopaedic Surgery, Sports Orthopedic Research Center - Copenhagen (SORC-C), Amager-Hvidovre Hospital, Faculty of Health Sciences, Copenhagen University, Copenhagen, Denmark 